\title{
Investigating the strength of alignment between Senior Phase mathematics content standards and workbook activities on number patterns
}

\begin{tabular}{|c|c|}
\hline \multicolumn{2}{|c|}{$\begin{array}{l}\text { Authors: } \\
\text { Agnes D. Qhibi }{ }^{1} \text { (I) } \\
\text { Zwelithini B. Dhlamini }{ }^{1} \\
\text { Kabelo Chuene }{ }^{1} \text { (D) }\end{array}$} \\
\hline \multicolumn{2}{|c|}{$\begin{array}{l}\text { Affiliations: } \\
{ }^{1} \text { Department of Mathemat } \\
\text { Science and Technology } \\
\text { Education, Faculty of } \\
\text { Humanities, School of } \\
\text { Education, University } \\
\text { of Limpopo, Polokwane, } \\
\text { South Africa }\end{array}$} \\
\hline \multicolumn{2}{|c|}{$\begin{array}{l}\text { Research Project Registration: } \\
\text { Project Number: } \\
\text { FHDC/2017/2520 }\end{array}$} \\
\hline \multicolumn{2}{|c|}{$\begin{array}{l}\text { Corresponding author: } \\
\text { Zwelithini Dhlamini, } \\
\text { zwelithini.dhlamini@ul.ac.za }\end{array}$} \\
\hline \multicolumn{2}{|c|}{$\begin{array}{l}\text { Dates: } \\
\text { Received: } 03 \text { Aug. } 2020 \\
\text { Accepted: } 20 \text { Oct. } 2020 \\
\text { Published: } 17 \text { Dec. } 2020\end{array}$} \\
\hline \multicolumn{2}{|c|}{$\begin{array}{l}\text { How to cite this article: } \\
\text { Qhibi, A.D., Dhlamini, Z.B., \& } \\
\text { Chuene, K. (2020). } \\
\text { Investigating the strength of } \\
\text { alignment between Senior } \\
\text { Phase mathematics content } \\
\text { standards and workbook } \\
\text { activities on number patterns. } \\
\text { Pythagoras, } 41(1) \text {, a569. } \\
\text { https://doi.org/10.4102/ } \\
\text { pythagoras.v41i1.569 }\end{array}$} \\
\hline $\begin{array}{l}\text { Copyright: } \\
\text { (c) 2020. The A } \\
\text { Licensee: AOS } \\
\text { is licensed und } \\
\text { Creative Comn } \\
\text { Attribution Lic }\end{array}$ & $\begin{array}{l}\text { Authors. } \\
\text { IS. This work } \\
\text { der the } \\
\text { nons } \\
\text { ense. }\end{array}$ \\
\hline 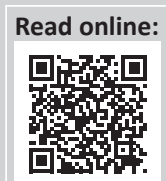 & $\begin{array}{l}\text { Scan this QR } \\
\text { code with your } \\
\text { smart phone or } \\
\text { mobile device } \\
\text { to read online. }\end{array}$ \\
\hline
\end{tabular}

Improving the strength of alignment between educational components is essential for quality assurance and to achieve learning goals. The purpose of the study was to investigate the strength of alignment between Senior Phase mathematics content standards and workbook activities on numeric and geometric patterns. The study contributes to strengthening the intended curriculum and the workbook activities, since workbooks are widely used in South African public schools. The study employed the concurrent triangulation research design. The theoretical framework comprised Webb's alignment model and the Surveys of Enacted Curriculum. The Senior Phase mathematics content standards and Department of Basic Education workbooks were selected for content analysis. The findings showed that the alignment between Senior Phase mathematics content standards and workbook activities on numeric and geometric patterns was significantly acceptable with misaligned content and representations that require urgent attention. We recommend reconfiguration of both the workbook activities on numeric and geometric patterns and Senior Phase mathematics content standards to align content, cognitive levels, representations and assessment. Further studies on teaching and learning that are aided by the workbook activities should be mandated.

Keywords: alignment index; cognitive levels; content standards; scale of agreement; number patterns.

\section{Introduction}

The investigation of the strength of alignment ensures synergy between curriculum components' main content standards, classroom instruction and assessment (Polikoff \& Porter, 2014; Porter, 2002). The extent of agreement between these curriculum components is referred to as alignment (Roach, Niebling, \& Kurz, 2008). The conceptualisation of alignment begins with common understanding of the educational components used in this discourse, content standards, classroom instruction and assessment. Kurtz, Elliott, Wehby and Smithson (2010) refer to these as follows: (1) the intended curriculum is reflective of the content standards as specified in the Curriculum and Assessment Policy Statement (CAPS) (Department of Basic Education [DBE], 2011); (2) the enacted curriculum refers to the content of instruction taught by teachers in classrooms; (3) the assessed curriculum is depicted by the content measured by the various forms of assessment or tests during the academic year. Hence, the conceptualisation between these three aspects of the curriculum in the alignment discourse is: the intended curriculum specifies content for instruction; the content taught by teachers during instruction portrays the enacted curriculum; the assessed curriculum depicts the assessed content that gauges levels of students' achievement. The investigation of the strength of alignment normally begins with the determination of the content, the cognitive levels and representations of each of the documents (Porter, 2002; Webb, 1997). Frequent studies on alignment are necessary to improve the agreement of curricula expectations, classroom instruction and assessment (Russell \& Moncaleano, 2020). Alignment is both horizontal and vertical. Horizontal is between curricula (intended and assessed) and assessments while vertical is between learning materials, classroom instruction, professional development and learner outcomes (enacted curriculum) (Webb, 1997). Hence, alignment has the potential to strengthen the connections between what is taught, what is tested and what is intended by the curriculum (Martone \& Sireci, 2009).

The importance of measuring the strength of alignment between educational components remains a prerequisite for any education system (Porter, 2002; Webb, 1997). Such importance hinges on the quality of content standards and how they filter to other educational components, such as assessment (Roach et al., 2008). The current study focuses on the intended curriculum, CAPS, which is referred to as the Senior Phase mathematics content standards (SPMCS) (DBE, 2011), and the 
assessed curriculum, the numeric and geometric patterns (NGP) workbook activities as an indication of what will be assessed in tests and exams. Roach et al. (2008) observe that high expectations are attached to educational materials used to support curriculum delivery. Similar expectations should be held of workbooks as they also play a role in supporting curriculum delivery. The influence of workbook activities on the quality of mathematics cannot be undermined when they serve as tools for practice, assessment and monitoring in schools (Hoadley \& Galant, 2016). More specifically, NGP content promotes the possibility of learners' generalisations from arithmetic to algebra (Kieran, 2004). Carraher, Schliemann, Brizuela and Earnest (2006) suggest that algebra and arithmetic are interconnected and should be integrated in elementary mathematics.

In 2012, the DBE in South Africa rolled out an initiative to provide workbooks to Grades 1-9 learners in public schools (Hoadley \& Galant, 2016). This initiative, as shown in other education systems, was aimed at providing practice and monitoring tools in the form of worksheets (DBE, 2013; Fleisch, Taylor, Herholdt, \& Sapire, 2011). Practice tools provide extended opportunities for learners to revisit content and skills that ought to have been introduced in an earlier learning experience (Hoadley \& Galant, 2016). In contrast, monitoring tools gauge the coverage of content as intended by the curriculum (Fleisch et al., 2011). A review of the literature indicated that a few studies were conducted on workbooks in South Africa (Fleisch et al., 2011; Hoadley \& Galant, 2016; Mathews, Mdluli, \& Ramsingh, 2014; Pausigere, 2017); however, there is a dearth of similar studies in Grades 7-9. Textbooks are learning materials that place the content of the intended curriculum in the context of teaching and learning (Roach et al., 2008). In contrast, workbooks supplement textbooks with worksheets for practice in preparation for tests and exams (Hoadley \& Galant, 2016). The unavailability of textbooks resulted in the use of workbooks as teaching tools by some teachers in Grade 3 and Grade 6 (Fleisch et al., 2011; Mathews et al., 2014). Similar practices may be expected with Grades 7-9 workbooks. It is, therefore, critical to frequently compare educational components, as pointed out by Hoadley and Galant (2016), in textbooks, workbooks, assessments and curricular content.

The aim of the study was to investigate the strength of alignment between SPMCS (DBE, 2011) and workbook activities on NGP (DBE, 2017a, 2017b, 2017c). One research question was posed: how are the workbook activities on numeric and geometric patterns aligned to the Senior Phase mathematics content standards as stated in CAPS (DBE, 2011)? This investigation of alignment has the potential to provide crucial information to policymakers that is essential for developing improved content structure (Mathews et al., 2014). This study contributes to the literature of quality educational support materials. It advances the literature in the methods of evaluating alignment of educational components, using the context of NGP. In addition, the simultaneous use of Porter's alignment model (quantitative) and Webb's (1997) alignment model (qualitative) signals the uniqueness of this study. Most studies on alignment use a single method, hence the current study has a methodological significance.

\section{Literature review}

\section{Alignment studies}

Alignment studies on educational components have been conducted internationally in various disciplines (FitzPatrick, Hawboldt, Doyle, \& Genge, 2015; Higgins, 2013). In South Africa, Ndlovu and Mji's (2012) alignment study was in mathematics, while Edwards's (2010) study was in physical sciences. Some of these studies used Webb's alignment model while others used the Surveys of Enacted Curriculum (SEC). The current study uses the following as tools for alignment: (1) the Grades 7-9 specification of mathematics content in numeric and geometric patterns, which is referred to as SPMCS, for uniformity of alignment language (DBE, 2011) and (2) workbook assessment activities on numeric NGP (assessed) (DBE, 2017a, 2017b, 2017c). The review of literature on NGP in the sections to follow provides the rationale for using this content area.

A handful of studies employed Webb's alignment with focus on investigating the alignment between content standards and assessment. FitzPatrick et al. (2015) conducted a study on the alignment between learning objectives and assessments used in Therapeutics courses in Canada. Findings from their study revealed misalignment between assessment and learning objectives, where some of the learning objectives, such as communicator, collaborator, manager and advocate, had no matches in the course examination. As a consequence, to learning, these outcomes might be regarded as less important by learners since they do not form part of the examination, which might conflate the course. Another alignment study was conducted between Common Core State Standards (CCSS) for mathematics Grade 8 and three assessments: the National Assessment of Educational Progress (NAEP), the American College Testing (ACT) EXPLORE and the Jefferson County Public School (JCPS) interim assessment (Higgins, 2013). The findings highlighted the fact that the CCSS for the Grade 8 mathematics were significantly aligned with the JCPS interim assessment. However, the other two assessments (the NAEP and the ACT EXPLORE) were found to be misaligned with the Grade 8 mathematics CCSS because of the implementation of new frameworks that neglected the CCSS framework. There is a likelihood that the two assessments (NAEP and ACT EXPLORE) might not meet the acceptable level of the CCSS.

An alignment study that employed SEC, and subsequently outlined the computed alignment index, was conducted by Ndlovu and Mji (2012). They explored alignment between the Trends in International Mathematics and Science Study (TIMSS) for the 2003 Grade 8 mathematics framework and the Revised National Curriculum Statement's (RNCS) (DBE, 2002) assessment standards. The findings of this study 
revealed that the alignment index of 0.751 had misalignment that was significantly low, in accordance with the Fulmer critical values. Also, the RNCS was found to be stronger in relation to knowledge and procedures under the three content categories (number, geometry and data) and weaker in terms of reasoning. Edwards (2010) also employed SEC to calculate the degree of alignment between Grade 12 Physical Sciences exemplar papers and the final examination dealing with the South African curriculum content. The findings exposed alignment indices ranging from 0.76 to 0.79 for the Physics component, which is higher than the Chemistry component which had alignment indices ranging from 0.52 to 0.69 . A huge discrepancy was obtained in the cognitive level 'remember' for both exemplar papers and the final examination. It is critical to cover the cognitive levels on the assessment as outlined by the curriculum to avoid discrepancies which result in misalignment.

The alignment studies reviewed above employed different alignment models which provided various dimensions, such as the content structure and the alignment indices. To justify the significance of the alignment indices, studies used Fulmer's indices (Ndlovu \& Mji, 2012; Polikoff \& Porter, 2014). However, this review indicates that the use of quantitative means falls short of the depth and specifics of the misaligned content and cognitive levels. In contrast, the use of qualitative means to investigate alignment (Webb, 1997) allows the determination of misaligned content, cognitive levels, content structure and ease of use of content (Qhibi, 2019). There is a dearth of literature that uses both quantitative and qualitative means to determine the strength of alignment, where commonly used alignment models are employed, such as Webb's model, SEC and the Achieve model. Hence the current study concurrently used Porter's and Webb's alignment models to corroborate alignment instead of testing significance quantitatively.

\section{Studies on Department of Basic Education workbooks}

Studies (Fleisch et al., 2011; Hoadley \& Galant, 2016; Mathews et al., 2014) were conducted on South African DBE workbooks whose primary purpose was to supplement textbooks and to provide learners with worksheets (DBE, 2013). As claimed by Hoadley and Galant (2016), the use of workbooks was not limited to monitoring implementation of the curriculum, but potentially they can inform quantitative coverage of the curriculum. Mathews et al. (2014) conducted a study that focused on the utilisation of DBE workbooks in a Grade 3 mathematics classroom. Their findings reveal that some teachers were using DBE workbooks for teaching and learning, and for assessment activities, while others were using them interchangeably with textbooks. Meanwhile, their primary purpose is to supplement textbooks and provide worksheets to the learners. This shows that some teachers are not using the workbooks as planned by the DBE. Another study focused on evaluating the Grade 6 mathematics DBE workbooks against the conventional textbooks in South Africa using quasi-experimental design (Fleisch et al., 2011).
Their findings highlighted the fact that learners who used conventional textbooks and those who used DBE workbooks exhibited the same improvement in mathematics performance. An alignment study was conducted by Hoadley and Galant between Grade 3 Literacy and Numeracy DBE workbooks and the CAPS, focusing on content coverage, weighting of content areas and cognitive levels. The findings revealed that the content for Grade 3 Literacy workbooks comprehensively matched the CAPS content; however, skills such as handwriting and listening were not matched with the skills in the workbooks. The alignment of the CAPS Grade 3 mathematics was strong in two content areas: (1) numbers, operations and relationships, and (2) patterns, functions and algebra. The alignment was moderate in another two content areas: (1) measurement and (2) data handling, while it was weak in one content area, namely space and shape. These findings suggest that the workbooks need to be strengthened in the future in areas where alignment was either moderate or weak.

\section{Numeric and geometric patterns}

The generalised focus of NGP systematically integrates concepts such as arithmetic, algebraic thinking and reasoning (Carraher et al., 2006). Usiskin (1988) conceptualises algebra instruction into the following tenets: '1) algebra as generalised arithmetic; 2) algebra as a study of procedures for solving certain kinds of problems;3) algebra as a study of relationships among quantities; 4) algebra as the study of structures' (pp. 11-15). These tenets form the basis of ascertaining the linking of the concepts that constitute NGP. On one hand, the structural conception, symbols are referred to as structures that generalise numeracy (Linchevski \& Livneh, 1999), and on the other hand, the procedural, computations with numbers lead to the need for some form of generality (Sfard, 1991, 1995). Algebra is used as a generaliser of patterns through the formation of generic structures (Kieran, 2004). For example, if one is required to find the 100th even number, first a protocol dealing with numbers multiplied by two is formed: ' $2 n$ '. ' 2 ' is the constant difference and ' $n$ ' is the position in the term, where ' $2 n$ ' constitutes the general rule of the sequence (DBE, 2011). Substituting into the protocol, the 100 th even number is computed to be constant difference $x$ position of the term: $2 n=2(100)=200$. The generalisation of patterns in elementary mathematics uses the difference and the position in a term of a mathematical expression to develop a generalised generic protocol which constitutes algebraic reasoning (Blanton \& Kaput, 2005).

In contrast, with the learners' conceptions that involve arithmetic computation of a constant difference, substitution in the protocol to determine any term in the sequence is referred to as algebraic thinking (Kieran, 2004; Pitta-Pantazi, Chimoni, \& Christou, 2020). In other instances, pictures from a context in the real world assist in learners' problem solving and manipulation of number patterns while making sense of relationship of concepts; this constitutes geometric reasoning (Pittalis \& Christou, 2010; Spangenberg \& 
Pithmajor, 2020). Du Plessis (2018) conceptualises geometric thinking processes in number patterns for Grades $\mathrm{R}-3$ as follows: (1) sequenced items, the use of a variety of geometric shapes to denote a pattern, (2) the core, full repeat of geometric items, and (3) the form, a representation of how the geometric items are arranged in the pattern. The findings of the study (Du Plessis, 2018) revealed the following discrepancies in the content and cognitive levels of the CAPS: (1) the absence of an indication of growth in cognitive complexity in numerical and geometric patterns; (2) the core and form in the geometric patterns were limited to sequencing and could not pose complex thinking and problem solving. This structure of the curriculum could result in fragmented algebraic thinking and reasoning that is associated with NGP. Results from other studies (Bishop, 2000; Girit \& Akyüz, 2016; Pitta-Pantazi et al., 2020) posed challenges with decreasing patterns, incorrectly assigned numbers where there were variables and generalising patterns where numeracy was not linked to algebra. These results show the persistent existence of algebraic thinking and reasoning in relation to numeric and geometric patterns (Bishop, 2000).

\section{Cognitive levels and standards in mathematics}

Cognitive levels distinguish the level of thinking and the appropriate depth of understanding (Zhuge, 2016). The most commonly used Bloom's taxonomy measures the cognitive domain in assessments ranging from low to higher order thinking (Irvine, 2017). In content alignment, the SEC (Porter, 2002) uses cognitive levels and Webb's alignment employs depth of knowledge to determine standards in the content used for instruction. The CAPS adapted the TIMSS cognitive levels to measure levels of thinking in mathematics assessments (DBE, 2011) comprising the following proportions: knowledge (25\%), routine procedures $(45 \%)$, complex procedures (20\%) and problem solving (10\%) (DBE, 2011). The TIMSS cognitive levels were considered to be coherent in cognitive component, content component and problem solving as key elements of mathematics thinking (Long \& Dunne, 2014).

DBE (2011) describes 'knowledge' questions as those that use mathematical facts, straight recall and appropriate mathematical vocabulary. In addition, 'routine procedures' are described as questions that need simple applications and steps (DBE, 2011). Kalobo and Du Toit (2015) highlight that 'complex procedures' involve unfamiliar problems or abstract problems that do not have a direct route to the solution, while 'problem solving' refers to unseen problems that require a higher level of cognitive skills and reasoning to solve problems. Cognitive levels were used in this study to code SPMCS and workbook activities on NGP in terms of their depth of understanding. One study used verbs to code RNCS assessment standards (Ndlovu \& Mji, 2012). Similarly, verbs on the content standards were used to code SPMCS while CAPS guidelines on cognitive levels were used to code workbook activities on NGP.

\section{Theoretical framework}

The theoretical framework for this study comprised two alignment models: Webb (Russell \& Moncaleano, 2020; Webb, 1997) and the SEC (Porter, 2002). Webb's alignment model uses content focus to judge alignment between content standards and assessment (Webb, 1997). Content standards in this case are SPMCS on NGP while assessment comprises DBE workbook activities on NGP. It consists of six content focuses, three of which look at content, cognitive levels and content representation (categorical concurrence, depth of knowledge consistency and range of knowledge correspondence). The focus of this study was on the qualitative part of Webb's model and adapted these first three content focuses. The other three content focuses, the structure of knowledge comparability, the balance of representation and the dispositional consonance, fell outside the scope of the study. Hence, the three Webb's content focuses employed in this study were as follows: (1) categorical concurrence, which verifies whether Grades 7-9 content standards and assessment cover the same content on both algebraic and geometric number patterns. In this study, consistency in content was verified between the Senior Phase mathematics content standards and the workbook activities on NGP; (2) Depth of knowledge consistency checks whether cognitive levels of content standards and assessments are in agreement. This content focus was verified if the cognitive levels between the workbook activities on NGP and SPMCS were in agreement; and (3) Range of knowledge correspondence checks how the representations of content standards are consistent in assessment. The range of knowledge correspondence covered on the SPMCS and the workbook activities on NGP were compared in this study to explore their status of alignment. In other studies, the model was employed to investigate alignment of content standards and assessments (Duke Escobar, 2016; FitzPatrick et al., 2015; Higgins, 2013; Smith, 2012).

The SEC was employed to compute alignment indices between SPMCS and workbook activities on NGP, where content proportions, assessment proportions and cognitive levels were used. Content proportions are fractions or percentages used to compare how much content is covered by the cognitive levels, while assessment proportions are the fractions of assessment covered by the cognitive levels. The cognitive levels distinguish and classify the ability to think, understand and solve problems (Zhuge, 2016). Mathematical thinking in NGP is both algebraic and geometric, the arithmetic computations of common difference and terms of a sequence using algebra and pictures (Pitta-Pantazi et al., 2020). In contrast, mathematical understanding refers to the problem solving strategies and complex thinking of NGP which is constituted in the process of generalising number patterns using algebraic and geometric reasoning (Blanton \& Kaput, 2005). Various studies have employed the SEC to investigate alignment between content standards, assessment and learning materials in terms of the alignment indices (Ndlovu \& Mji, 2012; Polikoff, 2015). Ndlovu and Mji (2012) describe 
the SEC as the most effective and simplest procedure for evaluating alignment. The SEC supplemented Webb's alignment model by outlining the degree of alignment in terms of the alignment indices. Hence Webb's alignment model and the SEC were adapted and deemed appropriate lenses for investigating the strength of alignment.

\section{Methodology and research design}

We employed mixed methods to investigate alignment between workbook activities on NGP and SPMCS. Qualitative and quantitative data were generated, analysed and corroborated through the concurrent triangulation design (Creswell, 2015). This design strengthened the findings of the study since limited knowledge exists about the alignment between workbook activities on NGP and SPMCS. Qualitative data using Webb's alignment model and quantitative data using Porter's alignment model were collected and analysed simultaneously to corroborate findings from the two data sets (Onwuegbuzie \& Combs, 2011). Figure 1 displays the procedure followed in implementing the design.

In this study, Webb's alignment guides the qualitative method. Qualitative content analysis explains patterns of content, cognitive levels and representations of the mathematics content standards and the workbook activities on NGP. Quantitative data were generated through Porter's alignment model. Correlational prediction design was used in this study. The criterion variable is the alignment index which provided the forecast of the outcome using content and cognitive levels, which were the predictor variables (Creswell, 2015).

\section{Document selection}

The following documents were purposively selected in order to investigate the alignment between SPMCS and DBE workbook activities on NGP: (1) DBE CAPS Grades 7-9 Mathematics (DBE, 2011), (2) DBE Workbook, Grade 7 Mathematics (English) Book 2 (DBE, 2017a), (3) DBE Workbook, Grade 8 Mathematics (English) Book 1 (DBE, 2017b) and (4) DBE Workbook, Grade 9 Mathematics (English) Book 1 (DBE, 2017c). The workbook activities on NGP were selected as this topic is crucial in the development of reasoning in algebra (Bryman, 2016; Etikan, Musa, \& Alkassin, 2016). Again, the selection of Senior Phase mathematics workbook activities on NGP was done to close the gap, since studies conducted on workbooks focused on Foundation Phase and Intermediate Phase (Fleisch et al., 2011; Mathews et al., 2014).

\section{Data collection}

Prior to data collection, DBE granted permission for the selection of the Senior Phase Mathematics CAPS document and DBE workbook activities on NGP. The university to which the authors are affiliated granted ethical clearance. The instruments for collecting quantitative data were adapted from the SEC (Porter, 2002); they were matrices of content with cognitive levels and assessment with cognitive levels. The adaptations were SPMCS on NGP with cognitive levels and workbook activities on NGP with cognitive levels (Table 4 and Table 5). Quantitative data were generated through mapping SPMCS and workbook activities on NGP with cognitive levels, and were represented by a score of 1 to represent a hit. A hit was used to show that content on SPMCS matched with content in workbook activities. In cases where content on SPMCS and workbook activities matched more than one cognitive level, the score was divided evenly using decimal fractions and sum to 1 . The content proportions and assessment proportions in the matrices for Grades 7-9 were used to compute the alignment indices. Parallel to computing

\begin{tabular}{|c|c|c|c|}
\hline Qualitative & Qualitative & \multirow{6}{*}{ 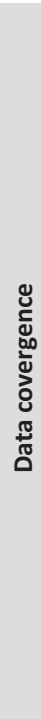 } & \multirow{6}{*}{ 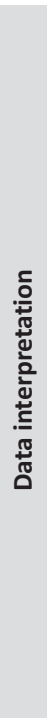 } \\
\hline Part 1 Phase 1: Data collection & Part 1 Phase 2: Data analysis & & \\
\hline $\begin{array}{l}\text { Webb (1997) was used to categorise SPMCS on } \\
\text { NGP and DBE workbook activities on NGP using } \\
\text { Webb's (1997) criteria of content focus: } \\
\text { categorical concurrence, depth of knowledge } \\
\text { consistency and range of knowledge correspondence. }\end{array}$ & $\begin{array}{l}\text { Data analysis was done through identifying the highest } \\
\text { consistency and commonality of hits between the content } \\
\text { analysts coding, as well as calculating the Krippendorff } \\
\text { alpha to measure agreements and disagreements between } \\
\text { the content analysts. This was done to examine the } \\
\text { categorical concurrence, depth of knowledge consistency } \\
\text { and range of knowledge correspondence in order } \\
\text { to analyse the content structure. }\end{array}$ & & \\
\hline Quantitative & Quantitative & & \\
\hline Part 1 Phase 1: Data collection & Part 1 Phase 2: Data analysis & & \\
\hline $\begin{array}{l}\text { Porter's (2002) alignment model was used to } \\
\text { generate quantitative data by categorising SPMCS } \\
\text { and DBE workbook activities on NGP through } \\
\text { content proportions and assessment proportions } \\
\text { to examine alignment indices. }\end{array}$ & $\begin{array}{l}\text { Data analysis was done through examining the } \\
\text { cognitive score points,total content proportions, proportions } \\
\text { grand total, alignment indices and discrepancies } \\
\text { to examine the degree of alignment indices }\end{array}$ & & \\
\hline
\end{tabular}

Source: Adapted from Qhibi, A.D. (2019). Alignment between senior phase mathematics content standards and numeric and geometric patterns' workbook activities. Unpublished Master of Education dissertation, University of Limpopo, Polokwane (p. 48)

FIGURE 1. Concurrent triangulation design. 
alignment indices, qualitative data were generated by mapping the SPMCS and workbook activities on NGP for categorical concurrence, depth of knowledge consistency and range of knowledge correspondence, which were identified as themes (Webb, 1997). Content on SPMCS and workbook activities on NGP was mapped on categorical concurrence, cognitive levels mapped on depth of knowledge consistency and ranges of patterns mapped on range of knowledge correspondence.

\section{Data analysis}

In line with how qualitative data were generated, and to evaluate the degree of alignment between SPMCS and workbook activities on NGP, data analysis was also based on categorical concurrence, depth of knowledge consistency and range of knowledge correspondence.

Three scales of agreement were adapted from Webb's content focus and were used to categorise the degree of alignment between SPMCS and workbook activities on NGP. They were: (1) full alignment, which depicted equal corresponding matches for content standards, cognitive complexity and knowledge comparisons, (2) acceptable alignment, which is sufficient matches in terms of content standards, cognitive levels and knowledge comparisons, and (3) insufficient alignment, in terms of exclusion from the workbook activities on NGP when compared to the requirements of the SPMCS (Webb, 1997). These scales of agreement were adapted from Webb's content focus and were used to categorise the degree of alignment between SPMCS and workbook activities on NGP. Three mathematics subject advisors were appointed as content analysts and trained on how to match the SPMCS and workbook activities on NGP. The Krippendorff alpha was employed to measure the agreements and disagreements between the content analysts (Krippendorff, 2011). The data analysis of the qualitative and quantitative data was done separately and corroborated afterwards.

The quantitative data were analysed following Porter's (2002) alignment model, which uses proportions of the content and assessment to compute the alignment indices. The proportions for content (SPMCS) and proportions for assessment (workbook activities) were calculated by dividing the proportions by the number of content standards and assessment activities. The alignment indices were calculated by adding the absolute differences of the content proportions and assessment proportions for all the content analysts on each grade. The absolute differences were then divided by 2 and the quotient was subtracted from 1 to obtain the alignment indices.

Alignment indices were then calculated using the formula: alignment index $=1-\frac{\sum\left|X_{1}-Y_{1}\right|}{2}$, where ' $X$ ' represents the cell proportions in the content matrix and ' $Y$ ' represents the cell proportions in the assessment matrix. Porter's rating scale ranges from 0 to 1 , where ' $0-0.5$ ' means no to moderate alignment and ' $0.51-1$ ' means moderate to perfect alignment.

\section{Quality criteria}

To ensure that the quantitative results are trusted, reliability and validity were assessed consistently throughout the study (Ivankova, 2014). The matrices used to compute Porter's alignment index were adapted by mathematics subject advisors (content analysts) from Porter's alignment model to ensure their content validity (Porter, 2002). Triangulation of data from the SPMCS and workbook activities on NGP resulted in the corroboration of the units of comparison in the three Webb's content focuses, namely categorical concurrence, depth of knowledge consistency and range of knowledge correspondence (Ivankova, 2014; Webb, 1997). To ensure interrater reliability of scales of agreements from the units of comparisons that the content analysts matched, their agreements and disagreements were measured using the Krippendorff alpha (Krippendorff, 2011; Zapf, Castell, Morawietz, \& Karch, 2016). The computed Krippendorff alpha of 0.999 was considered extremely reliable (Krippendorff, 2011). Finally, the simultaneous interpretation of results was ensured through the methodological triangulation of qualitative and quantitative data (Creswell \& Clark, 2017).

\section{Ethical consideration}

The permission for conducting this study was sought from, and granted by, the Department of Basic Education. Ethical clearance for the study was granted by the university to which the authors are affiliated. Ethical clearance number: TREC/10/2018:PG.

\section{Results}

The overall qualitative results for the alignment between the workbook activities on NGP and the SPMCS were on the scale 'acceptable alignment' using the three Webb's content focuses. On the other hand, the overall quantitative results indicated that the Porter's alignment index was in the range 'moderate to perfect' (0.73), for Grades 7-9. This signifies that $27 \%$ of content was either not covered by the workbook activities on NGP or not specified by the SPMCS, an indication of some misaligned content.

\section{Webb's alignment of SPMCS and workbook activities on NGP}

We outline the degree of alignment in terms of the three Webb's content focuses, namely categorical concurrence, depth of knowledge consistency and range of knowledge correspondence.

\section{Categorical concurrence}

This Webb's content focus was limited to investigating whether the content found in the workbook activities on NGP corresponded with the content required by the 
SPMCS. The subtopics were used as units of comparison for content standards required by the SPMCS that were compared to the content of the workbook activities on NGP (Table 1). The content analysts adapted Webb's scale of agreement as follows: (1) full alignment, equal corresponding matches of content in SPMCS and workbook activities on NGP, (2) acceptable alignment, sufficient matches of content in SPMCS and workbook activities on NGP, with a few missing concepts in the workbook activities, and (3) insufficient alignment, exclusion of content in the workbook activities on NGP that is required by the SPMCS. Ironically, some parts of content were included in the workbook activities on NGP and were not a requirement of the SPMCS in Grade 7 and Grade 8. The content analysts categorised this as 'out of scope'. Webb's scale of agreement lacks a category that would capture this content. Actually, Webb's scale of agreement matches from content standards (SPMCS) to assessments (workbook activities on NGP) and not vice versa, which is linear. Hence the 'out of scope' content was captured without matching but affected the final scale of agreement. Table 1 shows the comparison between content identified on SPMCS and workbook activities on NGP.

Table 1 illustrates the comparison between content identified by the content analysts on SPMCS and workbook activities on NGP as well as the scale of agreement between the two components. Most of the content identified on workbook activities matched with the content identified on SPMCS, where scales of agreement ranged from acceptable alignment to full alignment (Table 1). However, 'out of scope' content was also identified from the workbook activities on NGP. The

TABLE 1: Grades 7-9 categorical concurrence and scale of agreement.

\begin{tabular}{|c|c|c|c|c|c|c|}
\hline \multirow{3}{*}{$\begin{array}{l}\text { Content identified on } \\
\text { SPMCS }\end{array}$} & \multicolumn{6}{|c|}{ Content identified on workbook activities (NGP) } \\
\hline & \multicolumn{2}{|c|}{ Grade 7} & \multicolumn{2}{|c|}{ Grade 8} & \multicolumn{2}{|l|}{ Grade 9} \\
\hline & Content identified & Scale of agreement & Content identified & Scale of agreement & Content identified & Scale of agreement \\
\hline $\begin{array}{l}\text { Investigation and extension } \\
\text { of: } \\
\text { - Numeric patterns. }\end{array}$ & $\begin{array}{l}\text { Description of numeric } \\
\text { patterns. }\end{array}$ & Acceptable & $\begin{array}{l}\text { Identification of numeric } \\
\text { patterns. }\end{array}$ & Acceptable & $\begin{array}{l}\text { Extension of numeric } \\
\text { patterns. }\end{array}$ & Full \\
\hline $\begin{array}{l}\text { - Geometric patterns/ } \\
\text { patterns in physical or } \\
\text { diagrammatic form. }\end{array}$ & $\begin{array}{l}\text { Creation of geometric } \\
\text { patterns. } \\
\text { Representation of a } \\
\text { geometric pattern. }\end{array}$ & Full & $\begin{array}{l}\text { Extension of geometric } \\
\text { pattern. } \\
\text { Drawing of diagrams to } \\
\text { illustrate arithmetic } \\
\text { patterns. } \\
\text { Drawing of geometric } \\
\text { pattern. }\end{array}$ & Full & $\begin{array}{l}\text { Creation and completion } \\
\text { of geometric patterns. }\end{array}$ & Full \\
\hline $\begin{array}{l}\text { - Patterns with constant } \\
\text { difference. }\end{array}$ & $\begin{array}{l}\text { Description of patterns } \\
\text { with constant difference. }\end{array}$ & Acceptable & $\begin{array}{l}\text { Identification of constant } \\
\text { difference on numeric } \\
\text { patterns. }\end{array}$ & Acceptable & $\begin{array}{l}\text { Extension of pattern with } \\
\text { constant difference. }\end{array}$ & Full \\
\hline $\begin{array}{l}\text { - Patterns with constant } \\
\text { ratio. }\end{array}$ & $\begin{array}{l}\text { Description of patterns } \\
\text { with constant ratio. }\end{array}$ & Acceptable & $\begin{array}{l}\text { Identification of constant } \\
\text { ratio on numeric patterns. }\end{array}$ & Acceptable & $\begin{array}{l}\text { Extension of pattern with } \\
\text { constant ratios. }\end{array}$ & Full \\
\hline $\begin{array}{l}\text { - Patterns with neither } \\
\text { constant difference nor } \\
\text { ratio. }\end{array}$ & $\begin{array}{l}\text { Description of the rule } \\
\text { of patterns with neither a } \\
\text { constant difference nor ratio. }\end{array}$ & Acceptable & $\begin{array}{l}\text { Verifying patterns with } \\
\text { constant difference or } \\
\text { ratio. }\end{array}$ & Acceptable & $\begin{array}{l}\text { Extension of pattern with } \\
\text { neither constant difference } \\
\text { nor ratio. }\end{array}$ & Full \\
\hline $\begin{array}{l}\text { - Patterns from learners' } \\
\text { own creation. }\end{array}$ & Creation of own patterns. & Full & Creation of own patterns. & Full & Creation of own patterns. & Full \\
\hline $\begin{array}{l}\text { - Patterns represented in } \\
\text { tables. }\end{array}$ & $\begin{array}{l}\text { Completion of the table. } \\
\text { Writing of a pattern on } \\
\text { the table. }\end{array}$ & Full & $\begin{array}{l}\text { Completion of the table. } \\
\text { Recording of results on } \\
\text { the table. } \\
\text { Drawing and completion } \\
\text { of the table using } \\
\text { algebraic language. }\end{array}$ & Full & $\begin{array}{l}\text { Completion of the table. } \\
\text { Determination of the } \\
\text { terms on the table. }\end{array}$ & Full \\
\hline $\begin{array}{l}\text { - Patterns represented } \\
\text { algebraically. }\end{array}$ & - & & $\begin{array}{l}\text { Drawing and completion } \\
\text { of the table using } \\
\text { algebraic language. }\end{array}$ & Full & $\begin{array}{l}\text { Completion of the table } \\
\text { using the rule. } \\
\text { Making own rule and } \\
\text { completion of the table. }\end{array}$ & Full \\
\hline $\begin{array}{l}\text { Description of general rule } \\
\text { of patterns in own words } \\
\text { or in algebraic language. }\end{array}$ & $\begin{array}{l}\text { Description of the rule } \\
\text { in own words. }\end{array}$ & Full & $\begin{array}{l}\text { Stating of the rule. } \\
\text { Identification of the rule. }\end{array}$ & Full & $\begin{array}{l}\text { Description of the rule of } \\
\text { patterns. }\end{array}$ & Full \\
\hline- & $\begin{array}{l}\text { Description of patterns } \\
\text { represented by number lines. } \\
\text { Description of the rule } \\
\text { and the drawing of } \\
\text { number line. } \\
\text { Writing of pattern on a } \\
\text { number line. }\end{array}$ & Out of scope & $\begin{array}{l}\text { Calculation of number of } \\
\text { matchsticks used. }\end{array}$ & Out of scope & - & - \\
\hline- & $\begin{array}{l}\text { Solving of patterns in } \\
\text { context. }\end{array}$ & Out of scope & - & - & - & - \\
\hline - & $\begin{array}{l}\text { Writing of patterns in } \\
\text { algebraic language and } \\
\text { determination of their } \\
\text { values. } \\
\text { Calculation of the term given } \\
\text { the rule in } \\
\text { algebraic language. }\end{array}$ & Out of scope & - & - & - & - \\
\hline- & $\begin{array}{l}\text { Description of the } \\
\text { pattern and making a } \\
\text { diagram to show the value of } \\
\text { the term. }\end{array}$ & Out of scope & - & - & - & - \\
\hline
\end{tabular}

Source: Adapted from Qhibi, A.D. (2019). Alignment between senior phase mathematics content standards and numeric and geometric patterns' workbook activities. Unpublished Master of Education dissertation, University of Limpopo, Polokwane (pp. 65-80)

Note: Overall scale of agreement of content identified on workbook activities (NGP) for Grade 7 = Acceptable; Grade 8 = Acceptable; Grade $9=$ Full. 
Grade 7 workbook activities on NGP were restricted to the following content:

1. describe the rule for the pattern, $6,14,22,30$; describe the pattern, 2, 8, 32, 128, 512, ...

2. describe the pattern and draw a number line to show each, 8 , $10,14,20,28, \ldots$

3. describe the rule in your own words, $6,9,12,15, \ldots$

4. calculate the 20th term using a number sequence, 2, 5, 10, 17 .

(DBE, 2017a, p. 3-10)

These examples were limited to the description of number patterns, rules and drawing on number lines to show the patterns. The descriptions and drawings limited the extent of learners' investigation and extension of the NGP and did not allow justifications, as outlined in the SPMCS. The 'out of scope' content that appeared in the workbook activities were not matched since they were not required by the Grade 7 content standards. In Grade 7, the NGP are limited to a description in words and not in either drawings, algebraically or in context. However, such content was found in the Grade 7 workbook activities and deemed 'out of scope'. An example of content on workbook activities that was deemed 'out of scope' in Grade 7 was extracted from DBE workbook:

Thabelo is building a model house from matches. If he uses 400 matches in the first section, 550 in the second and 700 in the third section, how many matches will he need to complete the fourth section, if the pattern continues? (DBE, 2017a, p. 9)

Patterns in context were found to be 'out of scope', because the content did not form part of the content standards requirement for Grade 7. Furthermore, 'out of scope' content was also identified in Grade 8 workbook activities on NGP. The following example was extracted from the Grade 8 workbook:

Calculate the number of matchsticks used, 4th hexagon has 4 matchsticks per side (DBE, 2017b, p. 58)

This was considered out of scope since the skill of calculation was not outlined in the Grade 8 content standards. However, all content covered in the Grade 9 workbook matched the content with Grade 9 content standards. The scale of agreement between SPMCS and workbook activities on NGP under categorical concurrence was as follows: acceptable in Grade 7 and Grade 8, and full in Grade 9. The acceptable alignment was obtained where content of the workbook activities on NGP sufficiently matched the content on the content standards, while full alignment was obtained where content of the workbook activities on NGP fully matched the content on the content standards (Table 1). An example of Grade 9 workbook activities that fully matched the content on the content standards has been extracted from the Grade 9 workbook:

1. describe the pattern by giving the rule and then extend it with three more terms, $2,4,6,8,10, \ldots$

2. describe the pattern by giving the rule and then extend it by three terms, $2,4,8,16,32,64, \ldots$
3. describe the pattern by giving the rule and then extend it by three terms, $2,4,12,48,240, \ldots$

(DBE, 2017c, p. 68)

The content of these activities fully matched the content on the Grade 9 content standards, since extension and description of rules of patterns are requirements of Grade 9 content standards.

\section{Depth of knowledge consistency}

This Webb's content focus was employed to verify whether the workbook activities on NGP measured the same cognitive levels as the SPMCS. The cognitive levels emanated from the verbs of the NGP content standards in the SPMCS that determined the cognitive complexity. The cognitive levels were knowledge, routine procedures, complex procedures and problem solving, which were sourced from the SPMCS (DBE, 2011). The unit of comparison emanated from the matches of the cognitive levels of the SPMCS and those of the workbook activities on NGP (Table 2). The content analysts adapted Webb's scale of agreement as follows: (1) full alignment, equal corresponding matches of cognitive levels in SPMCS and workbook activities on NGP, (2) acceptable alignment, sufficient matches of cognitive levels in SPMCS and workbook activities on NGP, with a few missing cognitive levels in the workbook activities, and (3) insufficient alignment, exclusion of cognitive levels in the workbook activities on NGP that were required in the SPMCS. Table 2 illustrates the comparison of cognitive levels between SPMCS and workbook activities on NGP.

The data in Table 2 illustrate the comparison between cognitive levels identified in SPMCS and workbook activities on NGP as well as the scale of agreement of the two components. The cognitive levels of the workbook activities on NGP matched with the cognitive levels of the SPMCS, hence the scale of agreement fell on 'full alignment'. The only cognitive levels identified between the SPMCS and the workbook activities on NGP were knowledge and routine procedures. This was an indication that alignment between SPMCS and the workbook activities on NGP in terms of the cognitive levels was full. However, two cognitive levels, complex procedures and problem solving, were not covered by both SPMCS and workbook activities, an area for concern, since these cognitive levels should also be assessed as per CAPS requirements. The workbook activities on NGP in Grades 7-9 were limited to describe, calculate and draw. An example from the Grade 9 workbook activities on NGP is as follows:

1. Describe the pattern by giving the rule and then extend it by three terms,

1. $2,4,8,16,32,64, \ldots$

2. $25,5,1,0.2,0.04, \ldots$

(DBE, 2017c, p. 69)

The first pattern above required either knowledge of basic multiplication $(2 ; 2 \times 2 ; 2 \times 2 \times 2 ; 2 \times 2 \times 2 \times 2 ; 2 \times 2 \times 2 \times 2 \times$ 
TABLE 2. Grades 7-9 depth of knowledge consistency and scale of agreement.

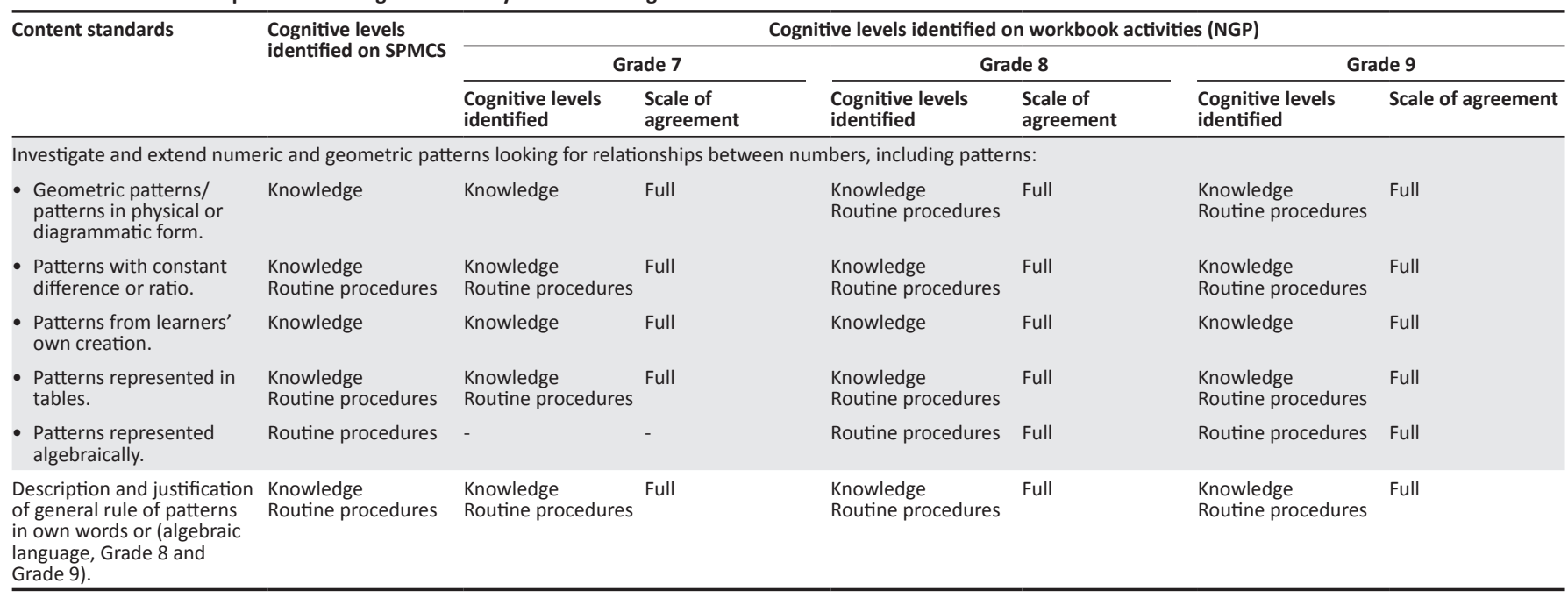

Source: Adapted from Qhibi, A.D. (2019). Alignment between senior phase mathematics content standards and numeric and geometric patterns' workbook activities. Unpublished Master of Education dissertation, University of Limpopo, Polokwane (pp. 84-100)

Note: Overall scale of agreement of Cognitive levels identified on workbook activities (NGP) for Grades 7, 8 and $9=$ Full.

$2 ; 2 \times 2 \times 2 \times 2 \times 2 \times 2)$ or knowledge of exponents $\left(2^{1} ; 2^{2} ; 2^{3}\right.$; $\left.2^{4} ; 2^{5} ; 2^{6}\right)$ to extend the pattern and determine the rule, while the second pattern required application of the simple procedure of dividing successive terms to get the difference, then deducing the rule. These workbook activities were matched with cognitive levels knowledge and routine procedures. The cognitive levels of these workbook activities matched with the cognitive levels of the Grade 9 content standards, as description and extension of patterns fell under cognitive levels knowledge and routine procedures on the content standards. Hence, the alignment between the workbook activities and Grade 9 content standards was full. These activities were limited to two cognitive levels, knowledge and routine procedures. The same applies to Grade 7 and Grade 8: only knowledge and routine procedures were covered in NGP workbook activities. An example extracted from the Grade 8 workbook is given below:

1. What is the constant difference or ratio between the consecutive terms?

$$
\text { 1. } 6,24,96,384
$$$$
\text { 2. } 8,2,-4,-10
$$

(DBE, 2017b, p. 56)

The first pattern above requires knowledge and simple procedure of multiplication and division $(6,6 \times 4,6 \times 4 \times 4,6 \times$ $4 \times 4 \times 4$ or $\left.\frac{24}{6}=4, \frac{96}{24}=4, \frac{384}{96}=4\right)$ to be able to determine the constant ratio. The second activity requires knowledge of integers and simple procedures of subtracting the previous term from the next term to be able to determine the constant difference. Hence, these activities fell under knowledge and routine procedures, which also matched the same cognitive levels of the Grade 8 content standards, where learners are expected to extend patterns with constant ratio. The scale of agreement between the Grade 8 content standards and workbook activities on NGP was fully aligned. The following activities were extracted from the Grade 7 DBE workbook:
1. Describe the pattern

$$
\text { 1. } 2,8,32,128,512
$$

2. Describe the pattern and draw a number line to show each 2. $10,9,7,4,0$

(DBE, 2017a, p. 5-6)

The first activity above requires knowledge of multiplication and the simple procedure of dividing the next term by the previous term to be able to describe how the pattern grows, whereas the second activity requires knowledge of integers, number lines and the simple procedure to subtract the previous term from the next term. Hence, these workbook activities fell under knowledge and routine procedures. These cognitive levels matched with the cognitive levels on the Grade 7 content standards, as description of patterns fell under knowledge and routine procedures. Moreover, the patterns in context that were found in the workbook for Grade 7 were labelled as problem solving by DBE whereas they, in fact, fell under knowledge and routine procedures. This is highlighted since problem solving require high levels of cognitive skills and reasoning to solve the problem (DBE, 2011; Kalobo \& Toit, 2015). An example of such a pattern in context is extracted from the Grade 7 workbook:

Lisa read 56 pages on Sunday, 66 pages on Monday, 76 pages on Tuesday, and 86 pages on Wednesday. If this pattern continued, how many pages would Lisa read on Thursday? (DBE, 2017a, p. 111)

The activity can be solved by adding 10 pages for the next day as the pattern is growing by 10 without engaging high level of cognitive reasoning. The workbook activities on NGP were configured using cognitive levels stipulated in the SPMCS. The overall scale of agreement on the depth of knowledge consistency was fully aligned. 


\section{Range of knowledge correspondence}

The SPMCS and the workbook activities on NGP were based on the range of content. The unit of comparison included the ranges of content standards' representations as required by the SPMCS and tested by the workbook activities on NGP (Table 3). The content analysts adapted Webb's scale of agreement as follows: (1) full alignment, equal corresponding matches of all forms of concept representations in the SPMCS and the workbook activities on NGP, (2) acceptable alignment, nearly all forms of concept representations in the SPMCS and workbook activities on NGP, and (3) insufficient alignment, exclusion of other forms of concept representations in the workbook activities on NGP that were required in the SPMCS. Surprisingly, there were certain forms of concept representations that were posed by the workbook activities on NGP which were not outlined on the SPMCS in certain grades, compelling the content analysts to categorise them as 'out of scope' (Table 3).

The data in Table 3 illustrate the comparison of ranges of patterns identified on the SPMCS and the workbook activities on NGP, as well as the scale of agreement between the two components. The scale of agreement between SPMCS and workbook activities on NGP for Grades 7-9 was 'acceptable'. All the ranges of pattern representations required by the SPMCS were covered by the workbook activities on NGP (full alignment), and out of scope ranges of patterns identified from workbook activities were also outlined (Table 3). Ironically, the workbook activities included ranges of patterns that were not outlined in the content standards, but were mentioned in the clarification notes. It would be good for ranges of patterns to be embedded in the content standards so as to ensure that these are not missed by users and also to clarify progression between the grades. Hence ranges of patterns are labelled 'out of scope' since the focus of the study was on content standards. The 'out of scope' ranges of pattern representations were as follows: (1) Grade 7: patterns represented algebraically, patterns represented on number lines, patterns in context, patterns with integers, patterns with whole numbers, patterns on drawing; (2) Grade 8: patterns with integers, patterns with whole numbers; (3) Grade 9: patterns with common fractions, patterns with decimal fractions. Examples that show 'out of scope' content on NGP are extracted from workbooks:

Grade 9: Describe the pattern by giving the rule and then extend it by three terms, $729,81,9,1, \frac{1}{9}, \frac{1}{81}$ (DBE, 2017c, p. 68)

Grade 7: Describe the pattern and draw a number line to show each, 8, 10, 14, 20, 28 (DBE, 2017a, p. 6)

The ranges of patterns for these workbook activities could not match the ranges of patterns on SPMCS, hence were deemed 'out of scope'. Figure 2 shows 'out of scope' content identified in Grade 7, which indicates the value of the term using drawing.

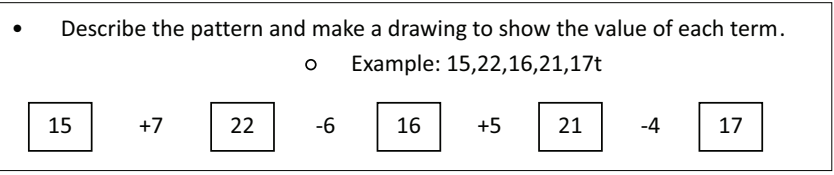

Source: Department of Basic Education (DBE). (2017a). Mathematics in English Grade 7 Book 2 Term 3 \& 4 (p. 110). Pretoria: Department of Basic Education. Retrieved from http:// www.education.gov.za

FIGURE 2: Number patterns represented on drawing.

TABLE 3: Grades 7-9 range of knowledge correspondence and scale of agreement.

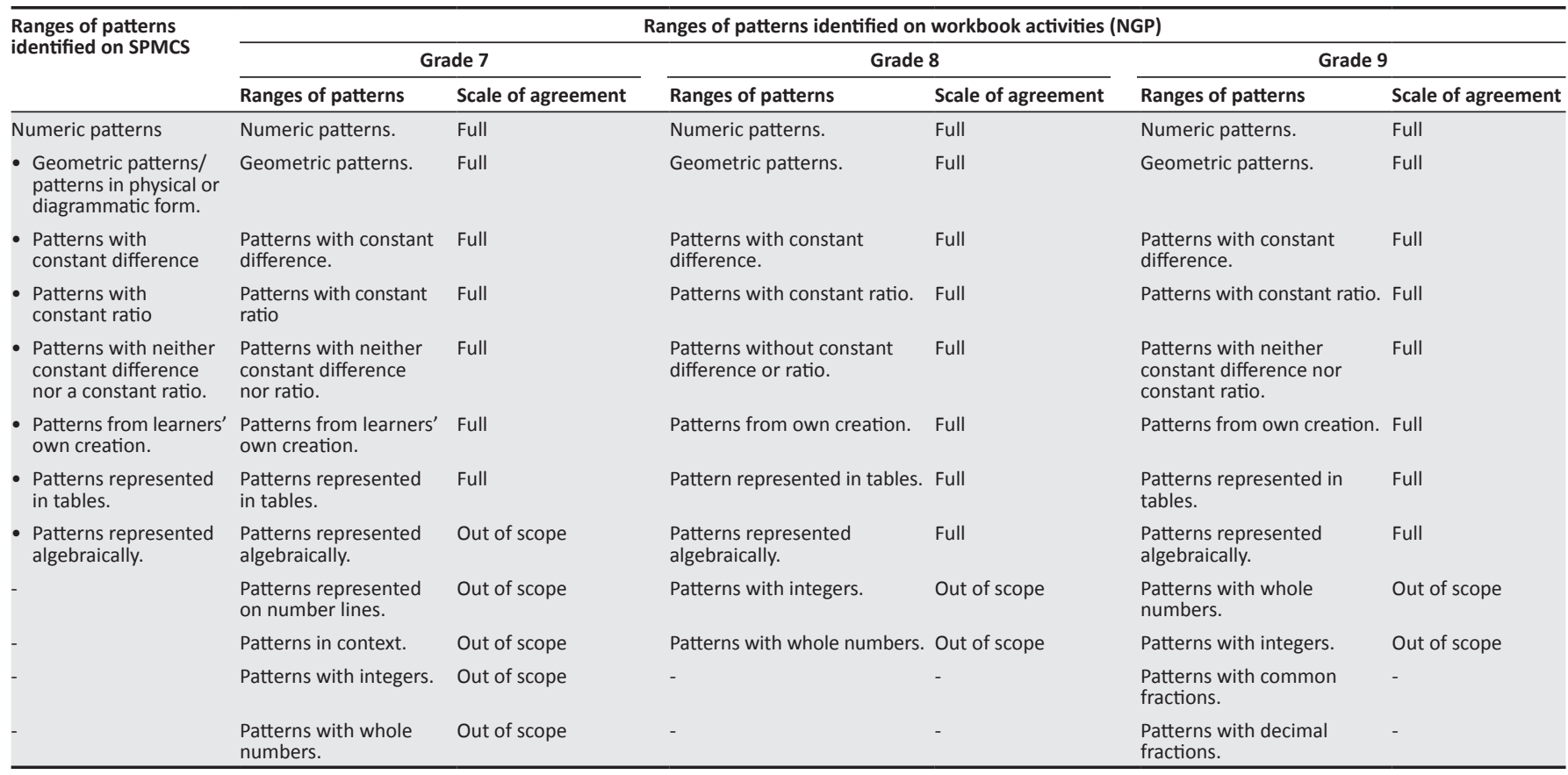

Source: Adapted from Qhibi, A.D. (2019). Alignment between senior phase mathematics content standards and numeric and geometric patterns' workbook activities. Unpublished Master of Education dissertation, University of Limpopo, Polokwane (pp. 105-112)

Note: Overall scale of agreement of ranges of patterns identified on workbook activities (NGP) for Grades 7, 8 and $9=$ Acceptable. 
This workbook activity was deemed 'out of scope' since description of patterns using drawing was not a requirement of the Grade 7 content standards. The scale of agreement between SPMCS and workbook activities on NGP under range of knowledge correspondence was as follows: acceptable alignment in Grades 7-9. This resulted in the overall scale of agreement on range of knowledge correspondence between SPMCS and workbook activities on NGP being 'acceptable alignment'.

\section{The computed Porter's alignment indices}

The computed Porter's alignment indices for Grades 7-9 are outlined in this section. The data in Table 4 outline a matrix of content standards (NGP) and cognitive levels for the initial process of computing Porter's alignment index. The content analysts recorded hits of the matches between SPMCS and cognitive levels. Their averages were divided by the total number of content standards (Table 4).

Table 4 shows the content matrix, the average content proportions generated by the content analysts by mapping content standards (SPMCS) with cognitive levels. The number of content standards in Grades 7-9 were two in each grade, hence the average content proportions matched by the content analysts were divided by two. These content proportions were then used in conjunction with the assessment proportions (Table 5) to calculate alignment indices.

The data in Table 5 are a synopsis of Porter's alignment of the assessment matrix for the workbook activities on NGP. The data were generated by content analysts by mapping workbook activities onto NGP with cognitive levels. The workbook activities on NGP were: 27 for Grade 7, 12 for Grade 8 and 7 for Grade 9. The said activities were matched to cognitive levels of mathematics (DBE, 2011). The content analysts recorded hits of the matches, and their averages were divided by the total number of workbook activities on NGP (Table 5). The two matrices (Table 4 and Table 5) were then used to calculate alignment indices between SPMCS and workbook activities on NGP. The quotients in Table 4 and Table 5 were substituted in the formula used to calculate the Porter's alignment index $\left(1-\frac{\sum\left|X_{1}-Y_{1}\right|}{2}\right)$. For example, the index for Grade 7 is 0.89 , which was computed as follows:

$$
1-\frac{|0.25-0.33|+|0-0|+|0-0|+|0-0|+|0-0|}{2}
$$

Similarly, Porter's alignment indices for Grade 8 and Grade 9 were computed to be 0.60 and 0.71 . These indices indicate that the alignment between the SPMCS and the workbook activities on NGP for Grades 7-9 are in the range 'moderate to perfect' alignment because they are in the range 0.51-1. The graphical representation of the alignment indices is shown in Figure 3.

The computed Porter's alignment indices were as follows: $0.89(89 \%)$ for Grade 7, 0.60 (60\%) for Grade 8 and $0.71(71 \%)$ for Grade 9. The information in Table 4 and Table 5 was also used to calculate discrepancies in cognitive levels between SPMCS and workbook activities on NGP. These discrepancies are illustrated in Figure 4.

Both weak and strong discrepancies were obtained between SPMCS and workbook activities on NGP in Grade 7, Grade 8 and Grade 9. A positive value depicts strong discrepancy, while a negative value portrays a weak discrepancy on NGP workbook activities for those cognitive levels. There was a strong discrepancy for knowledge in Grade 7, while the discrepancies for Grade 8

\begin{tabular}{|c|c|c|c|c|c|}
\hline \multirow[t]{2}{*}{ Grade } & \multirow[t]{2}{*}{ Content on NGP } & \multicolumn{4}{|c|}{ Cognitive levels } \\
\hline & & Knowledge & Routine procedures & Complex procedures & Problem solving \\
\hline \multirow[t]{3}{*}{7} & Investigation and extension of NGP & $\frac{0.5}{2}=0.25$ & $\frac{0.5}{2}=0.25$ & $\frac{0}{2}=0$ & $\frac{0}{2}=0$ \\
\hline & Description of the general rule of patterns in words & $\frac{0.5}{2}=0.25$ & $\frac{0.5}{2}=0.25$ & $\frac{0}{2}=0$ & $\frac{0}{2}=0$ \\
\hline & Total content proportions & 1 & 1 & 0 & 0 \\
\hline \multirow[t]{3}{*}{8} & Investigation and extension of NGP & $\frac{0.5}{2}=0.25$ & $\frac{0.5}{2}=0.25$ & $\frac{0}{2}=0$ & $\frac{0}{2}=0$ \\
\hline & $\begin{array}{l}\text { Description of the general rule of patterns in words or in } \\
\text { algebraic language }\end{array}$ & $\frac{0.5}{2}=0.25$ & $\frac{0.5}{2}=0.25$ & $\frac{0}{2}=0$ & $\frac{0}{2}=0$ \\
\hline & Total content proportions & 1 & 1 & 0 & 0 \\
\hline \multirow[t]{3}{*}{9} & Investigation and extension of NGP & $\frac{0.5}{2}=0.25$ & $\frac{0.5}{2}=0.25$ & $\frac{0}{2}=0$ & $\frac{0}{2}=0$ \\
\hline & $\begin{array}{l}\text { Description of the general rule of patterns in words or in } \\
\text { algebraic language }\end{array}$ & $\frac{0.5}{2}=0.25$ & $\frac{0.5}{2}=0.25$ & $\frac{0}{2}=0$ & $\frac{0}{2}=0$ \\
\hline & Total cognitive score points & 1 & 1 & 0 & 0 \\
\hline
\end{tabular}

TABLE 4: Grades 7-9 SPMCS matrix.

Source: Adapted from Qhibi, A.D. (2019). Alignment between senior phase mathematics content standards and numeric and geometric patterns' workbook activities. Unpublished Master of Education dissertation, University of Limpopo, Polokwane (pp. 126-132) 
TABLE 5: Grades 7-9 workbook activities on NGP matrix.

\begin{tabular}{|c|c|c|c|c|c|}
\hline \multirow[t]{2}{*}{ Grade } & \multirow[t]{2}{*}{ Content on NGP } & \multicolumn{4}{|c|}{ Cognitive levels } \\
\hline & & Knowledge & Routine procedures & Complex procedures & Problem solving \\
\hline \multirow[t]{3}{*}{7} & Investigation and extension of NGP & $\frac{6}{27}=0.22$ & $\frac{7.5}{27}=0.28$ & $\frac{0}{27}=0$ & $\frac{0}{27}=0$ \\
\hline & Description of the general rule of patterns in words & $\frac{4.5}{27}=0.17$ & $\frac{9}{27}=0.33$ & $\frac{0}{27}=0$ & $\frac{0}{27}=0$ \\
\hline & Total content proportions & 0.39 & 0.61 & 0 & 0 \\
\hline \multirow[t]{3}{*}{8} & Investigation and extension of NGP & $\frac{7.75}{12}=0.65$ & $\frac{2.75}{12}=0.23$ & $\frac{0}{12}=0$ & $\frac{0}{12}=0$ \\
\hline & $\begin{array}{l}\text { Description of the general rule of patterns in words } \\
\text { or in algebraic language }\end{array}$ & $\frac{0.75}{12}=0.06$ & $\frac{0.75}{12}=0.06$ & $\frac{0}{12}=0$ & $\frac{0}{12}=0$ \\
\hline & Total content proportions & 0.71 & 0.29 & 0 & 0 \\
\hline \multirow[t]{3}{*}{9} & Investigation and extension of NGP & $\frac{3.75}{7}=0.54$ & $\frac{1.75}{7}=0.25$ & $\frac{0}{7}=0$ & $\frac{0}{7}=0$ \\
\hline & $\begin{array}{l}\text { Description of the general rule of patterns in words } \\
\text { orin algebraic language }\end{array}$ & $\frac{0.75}{7}=0.11$ & $\frac{0.75}{7}=0.11$ & $\frac{0}{7}=0$ & $\frac{0}{7}=0$ \\
\hline & Total cognitive score points & 4.5 & 2.5 & 0 & 0 \\
\hline
\end{tabular}

Source: Adapted from Qhibi, A.D. (2019). Alignment between senior phase mathematics content standards and numeric and geometric patterns' workbook activities. Unpublished Master of Education dissertation, University of Limpopo, Polokwane (pp. 126-132)

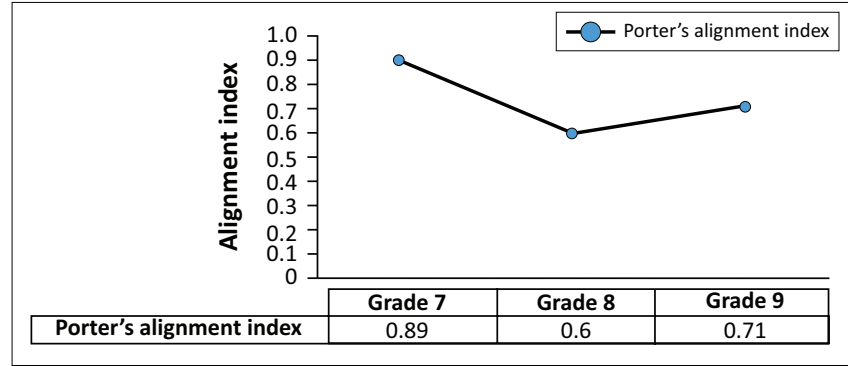

Source: Adapted from Qhibi, A.D. (2019). Alignment between senior phase mathematics content standards and numeric and geometric patterns' workbook activities. Unpublished Master of Education dissertation, University of Limpopo, Polokwane (p. 134)

FIGURE 3: Grades 7-9 alignment indices between Senior Phase Mathematics Content Standards and numeric and geometric patterns workbook activities.

and Grade 9 are weak. While there was a weak discrepancy in routine procedures in Grade 7, there was a strong discrepancy for Grade 8 and Grade 9. There were no discrepancies obtained for the three grades on complex procedures and problem solving because the discrepancy value was zero.

This study evaluated the strength of alignment between the SPMCS and workbook activities on NGP in terms of the content structure and the alignment indices. This evaluation is brought together in Table 6, which shows the results of the qualitative data analysis using Webb's alignment and quantitative data analysis using Porter's alignment.

The degree of alignment on the alignment indices ranges from 'moderate to perfect' which signifies a scenario that parts of the SPMCS and the workbook activities on NGP were misaligned.

\section{Discussion}

The aim of the current study was to investigate the strength of alignment between the SPMCS and workbook activities on
NGP. This study elucidates two remarkable results for the determination of misalignment. Firstly, Webb's alignment shows that certain parts of the SPMCS and the workbook activities on NGP were acceptable in content and representations, and fully aligned on cognitive levels. Secondly, the overall Porter's alignment index was in the range 'moderate to perfect' (0.73), positing some degree of bulk misalignment $(27 \%)$ of content and representations between SPMCS and workbook activities on NGP. In addition, complementarity between the two methods (Creswell \& Clark, 2017), Webb's and Porter's alignment models, clarified, enhanced and supplemented the findings by exposing alignment and misalignment of content, representations and the degree of alignment between the SPMCS and the workbook activities on NGP.

\section{Corroborating Webb's and Porters' alignment}

In this study, the corroboration of the quantitative and qualitative results in a concurrent mixed method replaces the calculation of the traditional statistical significance of the alignment index (Creswell \& Clark, 2017). The SEC involves computing the statistical significance using the ranges provided in Fulmer's critical values (Porter, 2002). To justify the significance of the results, we used the convergence model, that is, first compared and related Porter's alignment (73\%) and the overall Webb's alignment (acceptable) as shown in Table 6. Subsequently, both results were further scrutinised and interpretations made to justify the misalignment (Figure 5). The study by Ndlovu and Mji (2012) that aligned the RNCS and TIMSS concluded a computed Porter's alignment index of 0.751 which shows that the misalignment was significantly statistically low. The computed Porter's alignment index of 0.73 of the current study signals that $27 \%$ of the content and cognitive levels were misaligned. Porter (2002) made assertions that the alignment indices, as tools of measuring 


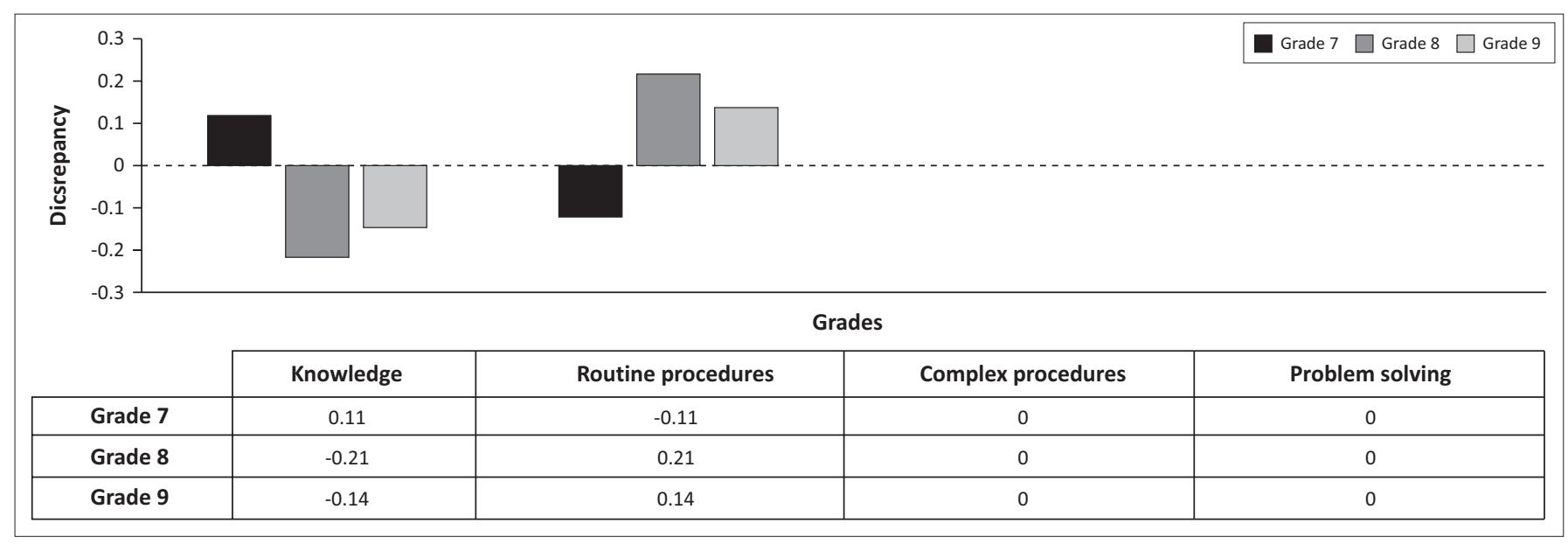

Source: Adapted from Qhibi, A.D. (2019). Alignment between senior phase mathematics content standards and numeric and geometric patterns' workbook activities. Unpublished Master of Education dissertation, University of Limpopo, Polokwane (p. 135).

FIGURE 4: Grades 7-9 discrepancies between Senior Phase Mathematics Content Standards and numeric and geometric patterns workbook activities.

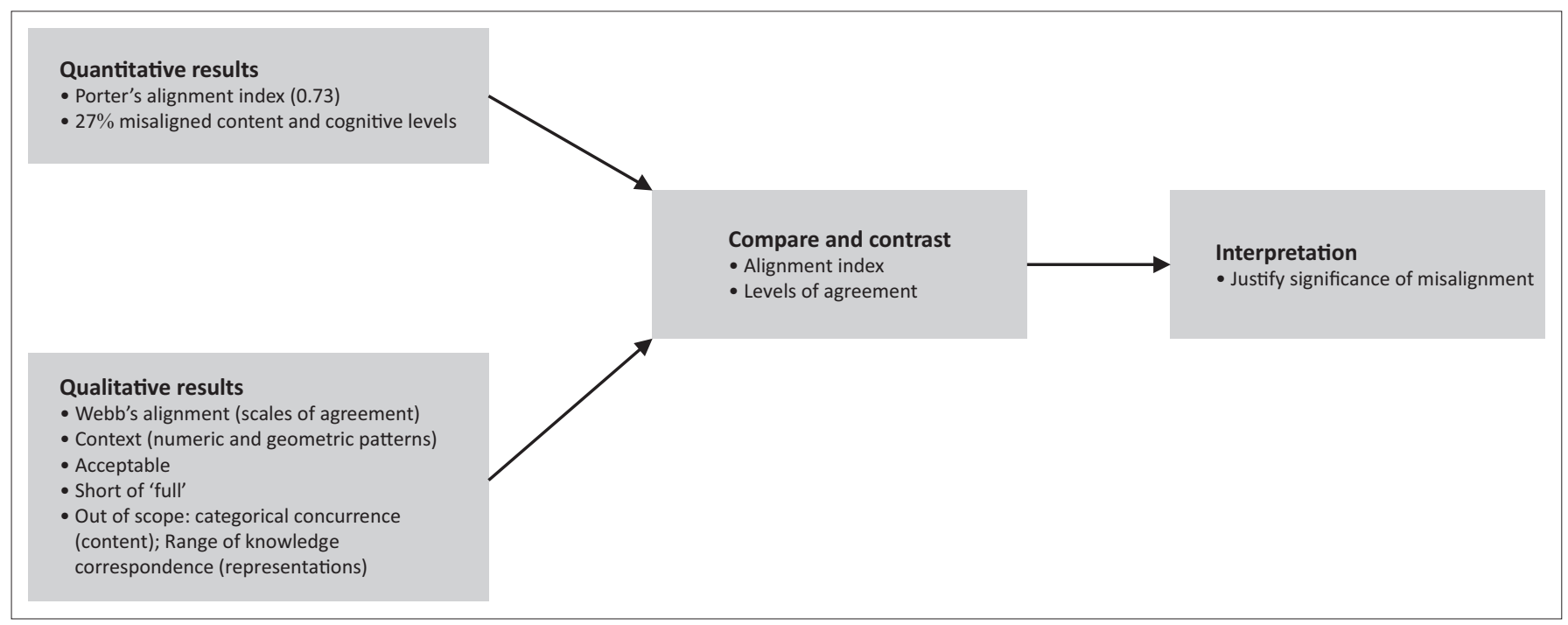

FIGURE 5: The convergence of the results.

alignment, are subject to extension and improvement. A handful of studies (Ndlovu \& Mji, 2012; Polikoff, 2015; Polikoff \& Porter, 2014) have used the alignment index to evaluate alignment between content and assessment. Noticeably, these studies made use of Fulmer's critical values to justify the significance of misalignment. However, in literature there is a dearth of extension that justifies the significance of the alignment in triangulation with qualitative methods. Hence, we compare and contrast Porter's alignment index with Webb's alignment procedure.

Webb's alignment posits alignment that is 'acceptable' for content and representations on the scales of agreement, categorical concurrence and range of knowledge correspondence, while depth of knowledge consistency was found to be fully aligned. The 'acceptable' finding posits sufficient matches in terms of content and representations, which is short of 'full'. This alignment is closely associated with the overall computed Porter's alignment index of 0,73 , which is in the range 'moderate to perfect'. Comparatively, the two alignment models, Porter's and Webb's, posit the same picture, that is, there are missing content and representations for SPMCS and workbook activities on NGP. According to Porter (2002), when the alignment index increases, it seems that there is better alignment, but the determination of good alignment based on the index is still unclear. Hence, making a judgement that $73 \%$ alignment is good could raise questions from policymakers who could claim the missing $27 \%$ content and representations would have an adverse effect on the content of NGP. In contrast, Webb's alignment was 'acceptable', with some content and representations that were coded 'out of scope', which also indicates some chunks of content that are either missing or misplaced in the wrong grade. Russell and Moncaleano (2020) advise that content standards that are not in agreement with assessment are more likely to fragment the enacted curriculum. Hence, the convergence of both Porter's and Webb's alignment results exposes weaker links between the intended and assessed curricula (Martone \& Sireci, 2009). 
TABLE 6: Summary of the research findings.

\begin{tabular}{|c|c|c|c|}
\hline \multirow[t]{3}{*}{ Grade } & \multicolumn{3}{|c|}{ Status of alignment } \\
\hline & \multicolumn{2}{|c|}{ Webb (1997) } & \multirow{2}{*}{$\frac{\text { Porter (2002) }}{\text { Alignment indices }}$} \\
\hline & Criteria of content focus & Level of agreement & \\
\hline \multirow[t]{3}{*}{ Grade 7} & Categorical concurrence & Acceptable & 0.89 \\
\hline & Depth of knowledge consistency & Full & \\
\hline & $\begin{array}{l}\text { Range of knowledge } \\
\text { correspondence }\end{array}$ & Acceptable & \\
\hline \multirow[t]{3}{*}{ Grade 8} & Categorical concurrence & Acceptable & 0.60 \\
\hline & Depth of knowledge consistency & Full & \\
\hline & $\begin{array}{l}\text { Range of knowledge } \\
\text { correspondence }\end{array}$ & Acceptable & \\
\hline \multirow[t]{3}{*}{ Grade 9} & Categorical concurrence & Full & 0.71 \\
\hline & Depth of knowledge consistency & Full & \\
\hline & $\begin{array}{l}\text { Range of knowledge } \\
\text { correspondence }\end{array}$ & Acceptable & \\
\hline Overall & - & Acceptable & 0.73 \\
\hline
\end{tabular}

Source: Adapted from Qhibi, A.D. (2019). Alignment between senior phase mathematics content standards and numeric and geometric patterns' workbook activities. Unpublished Master of Education dissertation, University of Limpopo, Polokwane (p. 144)

\section{Interpreting the convergence of Porter's and Webb's alignment}

The workbook activities are formative assessment and form part of the assessed curriculum (Hoadley \& Galant, 2016). Their role as practice tools hinges on closing the gaps between the intended and the enacted curricula in preparation for summative assessment, another level of the assessed curriculum (Kurtz et al., 2010; Mathews et al., 2014). Ideally, the summative assessment should be configured using the intended curriculum, the SPMCS (DBE, 2011). In Webb's alignment, there is 'missing' and 'out of scope' content and representations in the workbook activities when compared to the SPMCS; surely this reveals disagreement between these educational components.

Porter's alignment shows discrepancies on how the SPMCS and NGP workbook activities favoured knowledge and routine procedures in Grades 7-9 (Figure 4). Also, that is coupled with the absence of complex procedures and problem solving. In addition, the alignment index of $73 \%$ infers that $27 \%$ of content was not in agreement between the SPMCS and the NGP workbook activities. To interpret this convergence of the Porter's and Webb's results, we make reference to principles of the research design used in this study, the triangulation concurrent design, complementarity and integration (Onwuegbuzie \& Combs, 2011). Combining both the Porter's and Webb's results complements the existence of disagreements in content, cognitive levels and representations. This complementation of two data sources (Onwuegbuzie \& Combs, 2011) serves as the significance of the disagreements between the SPMCS and the NGP workbook activities.

The corroborated results that jointly revealed disagreements between the SPMCS and workbook activities pose concerns about the quality of the CAPS in NGP. Some content on NGP is hidden in the learning outcomes (DBE, 2011), while alignment in both the Webb's and Porter's procedures matches only the outcomes and the assessments
(Russell \& Moncaleano, 2020). In fact, alignment begins with the content standards and verifies the extent that content standard is available in the assessment (Porter, 2002). The methodological significance of the current study is the revelation of the missing (out of scope) content standards. There exists a dichotomy in the enacted curriculum: the workbooks activities supplement the intended curriculum. Surprisingly, there is a claim that workbooks were configured using the content standards (DBE, 2017a, 2017b, 2017c). Then, how can workbooks pose additional content than the intended curriculum (CAPS)? This implies a dilemma in the key aspects of the NGP content in these areas: (1) sequenced items, the algebra and geometric items were routine and could not extend to nonroutine, (2) the core, the repeat of the algebra and geometric components of the patterns could not demand problemsolving strategies and complex procedures, (3) the form, the formulation of the generic protocol lacked rigour due to the absence of non-routine problem solving and complex procedures.

The disagreements between the SPMCS and the NGP workbook activities poses mismatch in content progression in the following areas: (1) algebra and geometry as generalised arithmetic in numeric and geometric patterns. The absence of complex procedures in the workbook activities is an indication that the process of generalising number patterns using algebra and geometry is fragmented (Pittalis \& Christou, 2010; Usiskin, 1988). The rigour applied in the generalisation of algebraic and geometric patterns in the NGP workbook activities was only based on obvious common difference and position of a term and missing the abstract nature of complex procedures. Kalobo and Du Toit (2015) point out that complex procedures use abstract and unfamiliar problems. (2) Algebraic thinking should pose a range of simple to complex computations involving numeric and geometric patterns (Kieran, 2004; Pitta-Pantazi et al., 2020). The computations were limited to substitutions and simplifications in the generic protocols which lacked rigorous problem solving. In fact, in the workbooks they were referred to as problem solving, but during the analysis it was discovered that they lacked qualities of problem solving and were coded as routine procedures. Kalobo and Du Toit advise that problem solving refers to finding solutions for problems that require higher level of cognitive skills and reasoning. (3) Algebraic and geometric reasoning: the formulation of a generic protocol of NGP involved the difference in consecutive terms, the position in the sequence and pictorial patterns. Some of the learning outcomes that posed the investigation of number patterns lacked key elements of algebraic and geometric reasoning. They were also reduced to the use of the difference and position in the term. Long and Dunne (2014) advise that assessment activities should be configured using verbs such as describe, investigate and justify which should be found in the content standards to promote algebraic and geometric reasoning 
in NGP. There was an obvious lack of these verbs in the matching of the SPMCS and the NGP workbook activities.

\section{Conclusion}

This study contributes to the existing literature on teaching and learning support materials by investigating the strength of alignment between the SPMCS and workbook activities on NGP. The simultaneous use of Webb's alignment and Porter's alignment afforded the opportunity to study both the depth and quantity of the strength of alignment. The linearity of Webb's alignment requires reconfiguration to cater for 'out of scope' components during the matching. The dearth of studies that mix alignment methods afforded this study a contribution to existing literature which needs further research. Also, the reconfiguration of the Webb's alignment should result in the consideration of content that is misplaced in the content standards.

This study investigated solutions to the following initial research question: how are the workbook activities on numeric and geometric patterns aligned to the Senior Phase mathematics content standards? This investigation detected that, when configuring the workbook activities on NGP, reasonable attempts were made to conform to the SPMCS. However, some chunks of content and representations of the workbook activities on NGP were either missing in the workbooks or out of scope when compared to the SPMCS. This mismatch increases the possibility of negative effects on learners' ability to generalise algebra using arithmetic, algebraic thinking, and algebraic and geometric reasoning relevant for NGP. The complementation of the two approaches employed in this study leads to the conclusion that certain parts of the workbook activities on NGP and the SPMCS are misaligned with respect to content and representations. Some content and ranges of patterns were found in the workbook activities whereas they are not requirements of SPMCS. In addition, cognitive levels 'complex procedures' and 'problem solving' were not covered in SPMCS and NGP's workbook activities. Although the misalignment was low, its effects may be devastating to the algebraic and geometric cognitive development of learners. The provision of problem solving and complex procedures relevant to specific grades in the Senior Phase workbook activities on NGP requires urgent attention. There is dire need to reconfigure the workbooks to conform to the content requirements of the SPMCS for grades in the Phase, which could avoid conceptual meddling. These findings require further research on a larger scale in order to address other content areas of the workbooks. Also, further research is required on the pedagogical aspects of the workbook activities on the NGP which could inform the reconfiguration of the workbooks.

\section{Limitations}

This study was limited to numeric and geometric patterns, while the findings leave a dilemma for further studies that may cover other content areas and topics in the workbooks as learning support materials. Also, the alignment in the Senior
Phase paves the way for an opportunity for studies on conceptual progression that results from the observed misalignment.

\section{Implications for the teaching and learning of mathematics}

The review of literature indicated that most teachers in public schools use workbooks against the DBE's intentions of supplementing the enacted curriculum. Against this backdrop, the current study indicates misaligned and 'out of scope' content between the CAPS and NGP. The limitation of numeric and geometric patterns to routine problems deprives learners' abilities for problem solving and complex procedures. Where the need arises, where the workbooks supplement content standards that are missing in the CAPS, other complementary materials should be used to close that gap. Similarly, this argument can be extended for inclusion of non-routine complex procedures and problem solving to allow higher order algebraic and geometric thinking. The disagreements between the CAPS and the workbook activities creates opportunities for the fragmentation of conceptual progression of the NGP in the Senior Phase. If not addressed, the fragmentation of algebra problem-solving strategies is most likely to filter to higher grades and post school and cause difficulty in the learning of advanced algebra concepts. Policymakers and subject advisors should prioritise dissemination to teachers the supplementary content on problem solving and complex procedures to augment the discrepancies between CAPS and the NGP workbook activities.

\section{Acknowledgements}

This research emanates from the dissertation of the first author at the university of affiliation. We thank the content analysts for their professional work of coding the qualitative data and quantitative data.

\section{Competing interests}

There is no conflict of interest that links the authors to this article.

\section{Authors' contributions}

A.D.Q. was the student under the supervision of Z.B.D and K.C. Z.B.D. conceptualised the article, K.C. worked on the logical presentation of the ideas and the methodology, and A.D.Q. provided the first draft of the article.

\section{Funding information}

The research received no specific grant from any funding agency in the public.

\section{Data availability statement}

Data sharing is not applicable to this article as no new data were created or analysed in this study. 


\section{Disclaimer}

The views expressed in this article are those of the authors which are neither from policy nor those of the university of the authors' affiliation.

\section{References}

Bishop, J. (2000). Linear geometric number patterns: Middle school students' strategies. Mathematics Education Research Journal, 12(2), 107-126. https://doi. org/10.1007/BF03217079

Blanton, M.L., \& Kaput, J.J. (2005). Characterizing a classroom practice that promotes algebraic reasoning. Journal for Research in Mathematics Education promotes algeb
$36(5), 412-446$.

Bryman, A. (2016). Social research methods, London: Oxford University Press. Retrieved from http://www.academia.edu > Social_Research_Methods_4th_Edit

Carraher, D.W., Schliemann, A.D., Brizuela, B.M., \& Earnest, D. (2006). Arithmetic and algebra in early mathematics education. Journal for Research in Mathematics Education, 37(2), 87-115.

Creswell, J.W. (2015). Educational research: Planning, conducting, and evaluating quantitative and qualitative research. New York: Pearson.

Creswell, J.W., \& Clark, V.L.P. (2017). Designing and conducting mixed methods research. Thousand Oaks, CA: Sage.

Department of Basic Education (DBE). (2002). Revised National Curriculum Statement Grades R-9. Pretoria: Department of Basic Education.

Department of Basic Education (DBE). (2011). Curriculum and assessment policy statement: Senior phase Mathematics Grade 7-9. Pretoria: Department of Basic Education. Retrieved from http://www.education.gov.za

Department of Basic Education (DBE). (2013). Workbook training manual. Pretoria: Department of Basic Education. Retrieved from http://www.education.gov.za

Department of Basic Education (DBE). (2017a). Mathematics in English Grade 7- Book 2 Term 3 \& 4. Pretoria: Department of Basic Education. Retrieved from http:// www.education.gov.za

Department of Basic Education (DBE). (2017b). Mathematics in English Grade 8 Book 1 Term 1 \& 2. Pretoria: Department of Basic Education. Retrieved from http://www.education.gov.za

Department of Basic Education (DBE). (2017c). Mathematics in English Grade 9- Book 1 Term 1 \& 2. Pretoria: Department of Basic Education. Retrieved from http:// www.education.gov.za

Duke Escobar, V.G. (2016). An international comparison study of the alignment between standards and assessment of pre-service elementary Mathematics teacher standards and assessment of pre-service elementary Mathematics teacher
preparation courses. Retrieved from http://scholarworks.boisestate.edu/td/1217

Du Plessis, J. (2018). Early algebra: Repeating pattern and structural thinking at Foundation Phase. South African Journal of Childhood Education, 8(2), 1-11. https://doi.org/10.4102/sajce.v8i2.578

Edwards, N. (2010). An analysis of the alignment of the Grade 12 Physical Sciences examination and the core curriculum in South Africa. South African Journal of Education. 30(4), 571-590. https://doi.org/10.15700/saje.v30n4a389

Etikan, I., Musa, S.A., \& Alkassim, R.S. (2016). Comparison of convenience sampling and purposive sampling. American Journal of Theoretical and Applied Statistics, 5(1), 1-4. https://doi.org/10.11648/j.ajtas.20160501.11

FitzPatrick, B., Hawboldt, J., Doyle, D., \& Genge, T. (2015). Alignment of learning objectives and assessments in therapeutics courses to foster higher-orde thinking. American Journal of Pharmaceutical Education, 79(1), Art10. https://doi. org/10.5688/ajpe79110

Fleisch, B., Taylor, N., Herholdt, R., \& Sapire, I. (2011). Evaluation of Back to Basics Mathematics workbooks: A randomised control trial of the Primary Mathematics Research Project 1. South African Journal of Education, 31(4), 488-504. https:// doi.org/10.15700/saje.v31n4a466

Girit, D., \& Akyüz, D. (2016). Algebraic thinking in middle school students at different Grades: Conceptions about generalization of patterns. Necatibey Faculty of Education Electronic Journal of Science and Mathematics Education, 10(2) 243-272. https://doi.org/10.17522/balikesirnef.277815

Higgins, R.M. (2013). Examining alignment: National and local assessments and the common core state standards in Mathematics (unpublished PhD dissertation) common core state standards in Mathematics (unpublished PhD dissertation) (p. 617). University of
org/10.18297/etd/617

Hoadley, U., \& Galant, J. (2016). An analysis of the Grade 3 Department of Basic Education workbooks as curriculum tool. South African Journal of Childhood Education, 6(1), 1-12. https://doi.org/10.4102/sajce.v6i1.400

Irvine, J. (2017). A comparison of revised Bloom and Marzano's new taxonomy of learning. Research in Higher Education Journal, 33, 1-16.

Ivankova, N.V. (2014). Implementing quality criteria in designing and conducting a sequential QUAL $\rightarrow$ QUAN mixed methods study of student engagement with learning applied 'research methods online. Journal of Mixed Methods Research, 8(1), 25-51. https://doi.org/10.1177/1558689813487945

Kalobo, L., \& Du Toit, G.F. (2015). The use of Mathematics taxonomy in developing statistical learning outcomes for Grade 12 learners. International Journal of Educational Sciences, 9(3), 351-360. https://doi.org/10.1080/09751122.2015.11890325
Kieran, C. (2004). Algebraic thinking in the early grades: What is it? The Mathematics Educator, 8(1), 139-151.

Krippendorff, K. (2011). Agreement and information in reliability of coding. Communication Methods and Measures, 5(2), 93-112. https://doi.org/10.1080/1 9312458.2011 .568376

Kurtz, A., Elliott, S.N., Wehby, J., \& Smithson, J. (2010). Alignment of the intended planned, and enacted curriculum in general and special education and its relation to student achievement. The Journal of Social Education, 44(3), 131-145. https:// doi.org/10.1177/0022466909341196

Linchevski, L., \& Livneh, D. (1999). Structure sense: The relationship between algebraic and numerical contexts. Educational Studies in Mathematics, 40, 176-196. https://doi.org/10.1023/A:1003606308064

Long, C., \& Dunne, T. (2014). Mathematics curriculum and assessment: The role of taxonomies in the quest for coherence. Pythagoras, 35(2), 1-14. https://doi. org/10.4102/pythagoras.v35i2.240

Martone, A., \& Sireci, S.G. (2009). Evaluating alignment between curriculum, assessment, and instruction. Review of Educational Research, 79(4), 1322-1361. https://doi.org/10.3102/0034654309341375

Mathews, C., Mdluli, M., \& Ramsingh, V. (2014). The use of workbooks in South African Grade 3 Mathematics classrooms. South African Journal of Childhood Education, 4(1), 80-94. https://doi.org/10.4102/sajce.v4i1.118

Ndlovu, M., \& Mji, A. (2012). Alignment between South African Mathematics assessment standards and the TIMSS assessment frameworks. Pythagoras, 33(3), Art. \#182, 1-9 pages. https://doi.org/10.4102/pythagoras.v33i3.182

Onwuegbuzie, A.J., \& Combs, J.P. (2011). Data analysis in mixed research: A primer International Journal of Education, 3(1), E13:1-25. https://doi.org/10.5296/ije. v3i1.618

Pausigere, P. (2017). A sociological analysis of the pictures used in the South African foundation phase numeracy workbooks and their mathematical implications. Journal of Education, 70, 24-45. Retrieved from http://joe.ukzn.ac.za

Pittalis, M., \& Christou, C. (2010). Types of reasoning in 3D geometry thinking and their relation with spatial ability. Educational Studies in Mathematics, 75(2), 191-212. https://doi.org/10.1007/s10649-010-9251-8

Pitta-Pantazi, D., Chimoni, M., \& Christou, C. (2020). Different types of algebraic thinking: An empirical study on middle school students. International Journal of Science and Mathematics Education, 18, 965-984. https://doi.org/10.1007/ s10763-019-10003-6

Polikoff, M.S. (2015). How well aligned are textbooks to the common core standards in Mathematics? American Educational Research Journal, 52(6), 1185-1211. https://doi.org/10.3102/0002831215584435

Polikoff, M.S., \& Porter, A.C. (2014). Instructional alignment as a measure of teaching quality. Educational Evaluation and Policy Analysis, 36(4), 399-416. https://doi. quality. Educational Evaluation and

Porter, A.C. (2002). Measuring the content of instruction: Uses in research and practice. Educational Researcher, 31 (7), 3-14. https://doi.org/10.3102/0013189X 031007003

Qhibi, A.D. (2019). Alignment between senior phase mathematics content standards and numeric and geometric patterns' workbook activities. Unpublished Master of Education dissertation, University of Limpopo, Polokwane.

Roach, A.T., Niebling, B.C., \& Kurz, A. (2008). Evaluating the alignment among curriculum, instruction, and assessments: Implications and applications for research and practice. Psychology in the Schools, 45(2), 158-176. https://doi org/10.1002/pits.20282

Russell, M., \& Moncaleano, S. (2020). Examining the impact of a consensus approach to content alignment studies. Practical Assessment, Research, and Evaluation, 25, Art. \#4. https://doi.org/10.7275/k1c0-pk31

Sfard, A. (1991). On the dual nature of mathematical conceptions: Reflections on processes and objects as different sides of the same coin. Educational Studies in Mathematics, 22(1), 1-36. https://doi.org/10.1007/BF00302715

Sfard, A. (1995). The development of algebra: Confronting historical and psychological perspectives. Journal of Mathematical Behavior, 14, 15-39. https://doi. perspectives. Journal of Mathem
org/10.1016/0732-3123(95) $90022-5$

Smith, R.J. (2012). Alignment of intended learning outcomes, curriculum and assessment in a middle school science program (unpublished Master of Education dissertation). Edith Cowen University. Retrieved from http//www.ro.ecu.edu.au > theses

Spangenberg, E.D., \& Pithmajor, A.K. (2020). Grade 9 mathematics learners' strategies in solving number-pattern problems. EURASIA Journal of Mathematics, Science and Technology Education, 16(7), em1862. https://doi.org/10.29333/ejmste/8252

Usiskin, Z. (1988). Conceptions of school algebra and uses of variable. In A.F. Coxford \& P. Shulte (Eds.), The ideas of algebra, K-12, 1988 yearbook of the National Council of Teachers of Mathematics (NCTM) (pp. 8-19). Reston, VA: National Council of Teachers of Mathematics, 19

Webb, N.L. (1997). Criteria for alignment of expectations and assessments in Mathematics and science education. Research Monograph No. 6. Retrieved from http://www.semanticscholar.org > paper > Criteria-for-Alignment

Zapf, A., Castell, S., Morawietz, L., \& Karch, A. (2016). Measuring inter-rater reliability for nominal data - Which coefficients and confidence intervals are appropriate? BMC Medical Research Methodology, 16(1), 1-10. https://doi.org/10.1186/ s12874-016-0200-9

Zhuge, H. (2016). Multi-dimensional summarisation in cyber-physical society. Amsterdam: Morgan Kaufmann. https://doi.org/10.1016/B978-0-12-8034552.00010-X 